\title{
Springback prediction of CP2 titanium sheets in hydroforming with membrane diaphragm process with finite element method
}

\author{
Cahit Sertac Aydogan ${ }^{1, *}$, Hasan Ali Hatipoglu ${ }^{1}$, and Omer Keles ${ }^{2}$ \\ ${ }^{1}$ Tusas Aerospace Industries (TAI), Akıncı, Ankara, Turkey \\ ${ }^{2}$ Gazi university, Department of Mechanical Engineering, Maltepe, Ankara, Turkey
}

\begin{abstract}
This study aims to predict and to examine the springback of CP2 Titanium sheets in hydroforming with membrane diaphragm process, which is the branch of hydroforming process. The Hydroforming with Membrane Diaphragm was used for experimental investigation, in which specified CP2 titanium sheets were bent with various radii and angles on a specifically designed die. Springback results were then used to validate the finite element model constructed previously. Results show that the numerical model of this study can be used to predict the approximate springback values. Thus, the scrap quantities of the sheet metal titanium products can be reduced by making some modifications on the die, such as the springback compensation based on the obtained approximate springback values.
\end{abstract}

Keywords: Hydroforming, Springback, Finite element method (FEM)

\section{Introduction}

The Hydroforming with membrane diaphragm is a type of forming process. In this technique, a chamber filled by the fluid is covered by an elastic diaphragm. The surface of the diaphragm behaves as a comprehensive punch that can fit any shape of a rigid die by the action of fluid pressure (Fig. 1). The advantages of the process are that there is less springback value of the sheet, strain distribution is more even compare to other methods because of the smooth effect of fluid pressure and lastly, high quality parts with less damage to the sheet. The disadvantages are that high capacity press is needed to withstand the high pressures (up to $80 \mathrm{MPa}$ ) in the chamber; this method is suitable for producing a small number of parts. Finally, design precautions must be taken to avoid the tearing or wrinkling of parts because final geometry of the part is more challenging than in conventional stamping. So, qualified skilled workforce is needed.

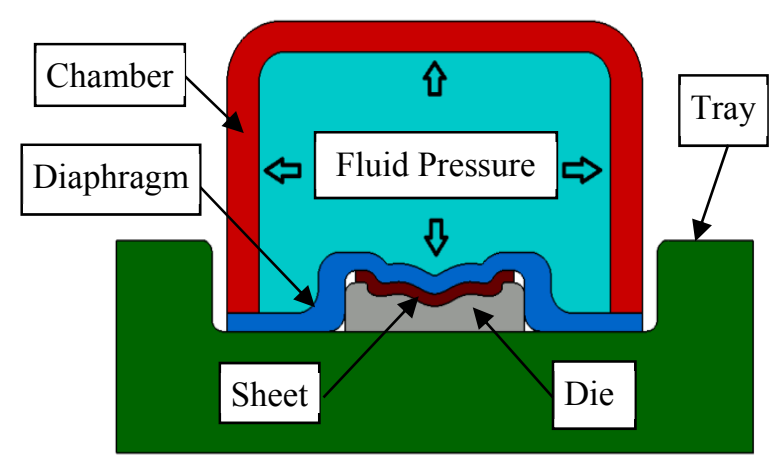

Fig. 1. Schematic representation of the Hydroforming with Membrane Diaphragm.
Some studies are found in literature related to this process. Hatipoglu et al. [1] studied about hydroforming with membrane diaphragm process, which was modeled by finite element method. Three experiments were conducted which is bending of a straight and contoured flange specimen and bulging of a circular specimen made of Aluminum 2024 T3. By these experiments, the influences of bend radius, blank thickness, flange length and orientation of the rolling direction of the specimen were examined. Experimental and numerical results were compared with each other.

Kulkarni and Prabhakar [2] aimed at developing a predictive finite element technique for the springback of aluminum 2024-T3 and 2024-O. Experiments were implemented to various bend angles and part thicknesses. Then, results were compared to finite element model findings. Palaniswamy et al. [3] studied about the springback reduction in the flexforming process by using optimized blank dimensions. The flexforming process is similar to the forming operations in stamping but is carried out in a fluid form cell. In the fluid form cell, a press ram with the oil and a flexible rubber diaphragm replaces the solid punch in a conventional press. Besides, sensitivity analysis was performed to demonstrate the influence of the friction coefficients and the initial blank dimensions for the cone shaped parts.

Dirikolu and Akdemir [4] examined the effect of parameters for the simulation of flexible forming process, which is another name of the hydroforming with membrane diaphragm, such as rubber hardness, blank material type, contact friction and die design. In another study, Yamashita et al. [5] investigated the applicability

\footnotetext{
* Corresponding author: caydogan@tai.com.tr
} 
of the numerical simulation for the Maslennikov's sheet metal drawing technique. The effect of the forming parameters was investigated, such as dimension and hardness of the rubber ring, friction coefficients and mechanical properties of the sheet.

Aim of the paper is to investigate the numerical modeling of the Hydroforming with membrane Diaphragm Process mainly focusing on the springback problem. Experimental work was done for the validation of the numerical model. Firstly, the experimental setup was submitted and the experimental results were discussed. Then, the numerical model was presented and the numerical results were compared to the experimental results.

\section{Experimental setup}

Blank dimensions were $60 \mathrm{~mm}$ width, $100 \mathrm{~mm}$ length and $0.5 \mathrm{~mm}$ thickness for the experiments. CP2 Titanium was used as the work piece material. The blanks were located on a die, which was specifically designed for the experimental purpose using locator pins. The rolling direction was parallel to the bending line. Experiments were repeated three times for each condition and the average of the obtained results taken. Experiments were carried out at $60 \mathrm{MPa}$ for the working pressure. All measurements were carried out by Mitutoyo 187-907 protractor with 5" precision. Experiments were conducted on Fluid cell press from Quintus technologies, which have $1.2 \mathrm{~m}$ width, $3 \mathrm{~m}$ length and $0.27 \mathrm{~m}$ height rectangular forming trays (Fig. 2).

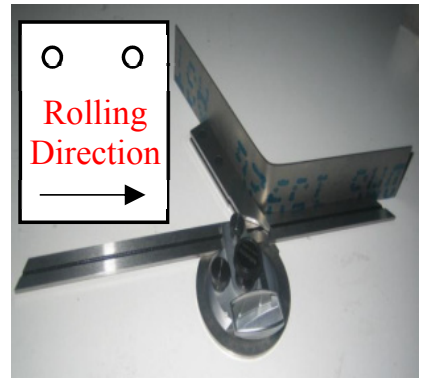

a)

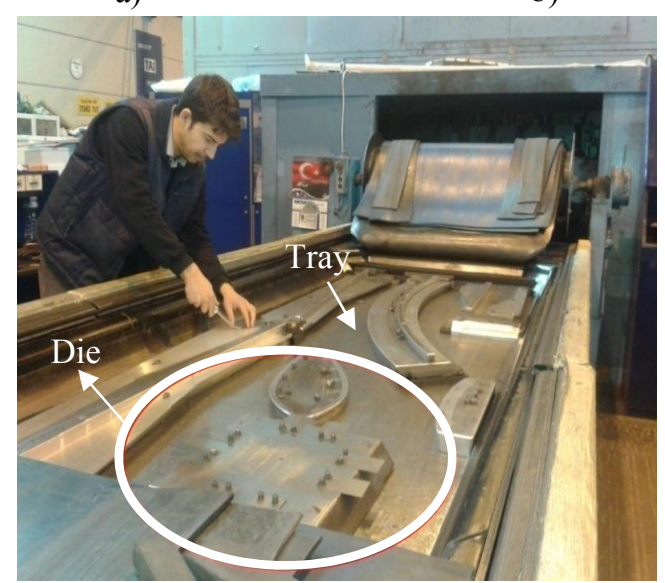

c)

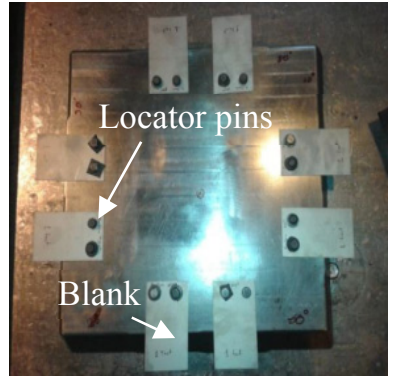

b)

\subsection{Die design}

The die was designed bilaterally which has $0^{\circ}, 60^{\circ}, 70^{\circ}$, $80^{\circ}, 90^{\circ}, 100^{\circ}, 110^{\circ}, 120^{\circ}$ bending angles and has 2 and $5 \mathrm{~mm}$ radii. AISI 1040 steel was used as the die material. Suitability of the mechanical properties and easy presence was the main criteria to choose this material. The die was modelled by using Catia V5-R20 software programme (Fig. 3).

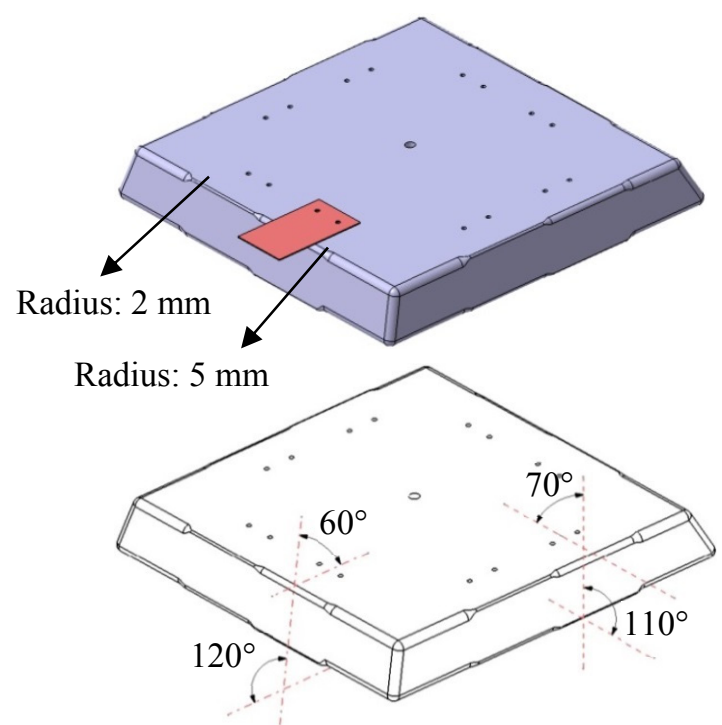

Fig. 3. Cad model of the die

\section{Numerical modelling}

Numerical models of physical experiments were prepared by using Dynaform software and solved by Ls-Dyna solver. Fig. 4 shows the three bodies in the model: the die (rigid), the blank (plastically deformable) and the diaphragm (elastically deformable). The springback phenomenon can be described as a combination of two stages. First stage is the forming and second stage is the unloading, in which work piece elastically recovers itself. Explicit scheme was used for the loading (forming) stage and implicit scheme was used for the unloading (springback) as suggested in Noels et al. [6].

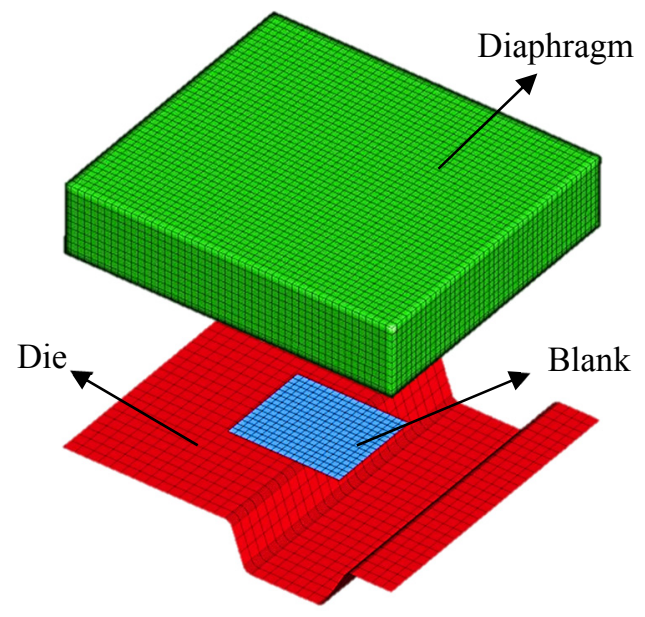

Fig. 4. Parts in the numerical model.
Fig. 2. (a) Protractor and scheme of the rolling direction. (b) Specifically designed die with locator pins and 8 specimens. (c) Fluid cell press from quintus technologies with the specifically designed die.

\footnotetext{
Fig. 4. Parts in the numerical model.
} 


\subsection{Mesh structure and element type}

The blank was divided into $2 \times 2 \mathrm{~mm}$ fully integrated shell element using 5 integration points through the thickness. The mesh was then refined to $0.5 \times 0.5 \mathrm{~mm}$ elements at critical areas such as the bending zone by using adaptivity algorithm. This algorithm reduces the computation time drastically. The die was divided into meshes, which depend on mesh parameter to maximum size $(4 \mathrm{~mm})$, minimum size $(0.1 \mathrm{~mm})$, chordal deviation $(0.1 \mathrm{~mm})$ and angle change for adaptivity $\left(5^{\circ}\right)$. The diaphragm was divided into $2 \times 2 \times 2 \mathrm{~mm}$ constant stress solid elements (Fig. 5).
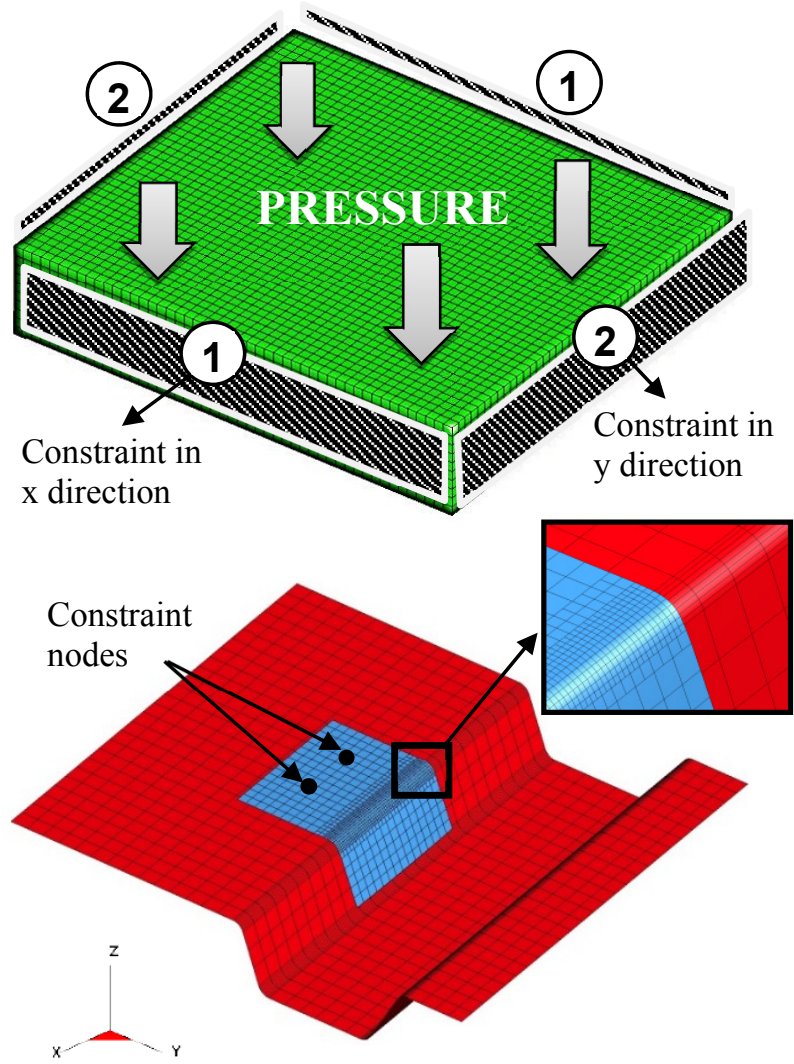

Fig. 5. Mesh structure and boundary conditions of the system.

\subsection{Boundary conditions}

Applied pressure destabilizes the system by forcing diaphragm to flow in the $\mathrm{x}$ and $\mathrm{y}$ directions. Therefore, the edge nodes of the diaphragm were constrained in the $\mathrm{x}$ and $\mathrm{y}$ directions to prevent any motion. For the blank, the two nodes were constrained in all directions to simulate locator pins (Fig. 5).

Loading curve (pressure vs time curve) is essential in slow-dynamic-explicit analysis. The trend of the curve should minimize the dynamic effects in the process [7]. In this case, the slope of the curve in the first region is low where the diaphragm is moving and enclosing the die, while the slope of the curve in the second region is high where the diaphragm is more stationary (Fig. 6).

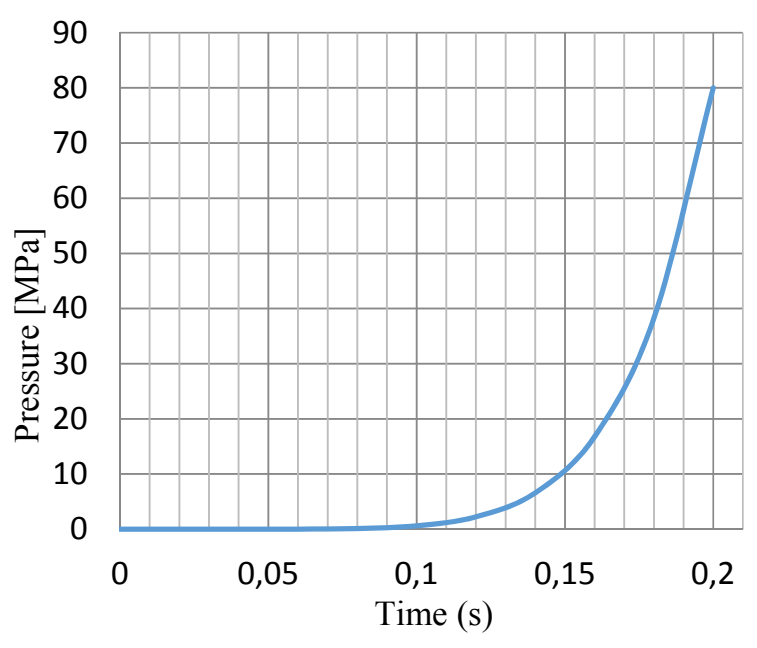

Fig. 6. The loading curve used in the analysis.

\subsection{Contact features and friction coefficient}

Definition of the contact algorithm between surfaces (diaphragm-die, diaphragm-blank, die-blank) is important to obtain precise and correct solutions in sheet metal forming applications. Penalty method was used for the contact algorithm and Coulomb model was used for friction. Friction coefficient between blank (Titanium) and die (Steel) was accepted as 0.365 , according to Adamus [8]. A special scaling factor was applied for the contact stiffness between diaphragm and the die, also between the diaphragm and the sheet in order to compensate the bulk modulus differences between these materials [1].

\subsection{Material characterization}

The materials in the process were CP2 Titanium for the blank, rubber for the diaphragm and AISI 1040 steel for the die. Mechanical properties of these materials were obtained from uniaxial tensile (ASTM E 8M for CP2 Titanium and ASTM D 412 for rubber). These mechanical properties were supplied from TAI (Turkish Aerospace Industry). Hollomon law was used for the flow curve of $\mathrm{CP} 2$, which is implemented by the following equation:

$$
\sigma=K \times \varepsilon^{n}
$$

Where $\mathrm{K}$ is the strength coefficient, $\mathrm{n}$ is the hardening exponent, $\sigma$ is the effective stress, $\varepsilon$ is the effective strain. Barlat 3-parameter anisotropic function was implemented for the yield surface. Mooney-Rivlin material model was used for the rubber. The strain energy density function is given in Mooney-Rivlin by:

$W=\sum_{k+m=1}^{n} C_{k m} \times\left(I_{1}-3\right)^{k}+\left(I_{2}-3\right)^{m}+\frac{1}{2} K \times\left(I_{3}-1\right)^{2}$

$I_{1}, I_{2}$ and $I_{3}$ are the strain invariants. $\mathrm{K}$ is the bulk modulus and $\mathrm{I}_{3}=1$ for incompressible materials. Two-parameter Mooney-Rivlin model ( $\mathrm{n}=1$ in Eq. (2)) was used. The Mooney-Rivlin constants $\left(\mathrm{C}_{01}, \mathrm{C}_{10}\right)$ were obtained from experiments [9]. Lastly, the die was accepted as rigid 
body. The necessary mechanical data used for the material models is summarized in Table 1 (supplied by TAI).

Table 1. Material data for CP2 titanium, AISI 1040 and rubber.

\begin{tabular}{|c|c|c|c|}
\hline \multicolumn{4}{|c|}{ Materials } \\
\hline Properties & $\underline{\mathrm{CP} 2}$ & $\underline{\text { Rubber }}$ & $\begin{array}{l}\underline{\text { AISI }} \\
\underline{1040}\end{array}$ \\
\hline Density, $\rho\left[\mathrm{t} / \mathrm{mm}^{3}\right]$ & 4.52E-09 & $1.00 \mathrm{E}-09$ & $7.80 \mathrm{E}-09$ \\
\hline Elastic modulus, E [MPa] & 111500 & 6 & 207000 \\
\hline Poisson's ratio, $v$ & 0.31 & 0.49 & 0.34 \\
\hline Yield strength, $\sigma_{0}[\mathrm{MPa}]$ & 452 & & \\
\hline Anisotropy value, $\mathrm{R}_{0}$ & 0.8 & & \\
\hline Anisotropy value, $\mathrm{R}_{45}$ & 2.03 & & \\
\hline Anisotropy value, $R_{90}$ & 2.43 & & \\
\hline $\begin{array}{l}\text { Strength coefficient, } \\
\mathrm{K}[\mathrm{MPa}]\end{array}$ & 742 & & \\
\hline Hardening exponent, $\mathrm{n}$ & 0.105 & & \\
\hline $\begin{array}{l}\text { Mooney-Rivlin constant, } \\
\mathrm{C}_{10}[\mathrm{MPa}]\end{array}$ & & 0.8 & \\
\hline $\begin{array}{l}\text { Mooney-Rivlin constant, } \\
\mathrm{C}_{01}[\mathrm{MPa}]\end{array}$ & & 0.2 & \\
\hline
\end{tabular}

\subsection{Energy controls and units}

Increasing the speed of process allow the analysis to take less computer time. However, virtual inertial effect resulting from the high process speed may lead to erroneous solutions, since the sheet metal bending process is quasi-static. For this reason, the speed of the process should be adjusted not to exceed a certain limit [10]. Generally, Energy files should be examined whether the kinetic energy exceeded $10 \%$ of internal energy or not. As seen from figure 7 , the kinetic energy does not exceed $10 \%$ of internal energy, so the acceptable quasi-static solution can be obtained. The unit system used was mm$\mathrm{s}-\mathrm{t}-\mathrm{N}$ at the simulations.

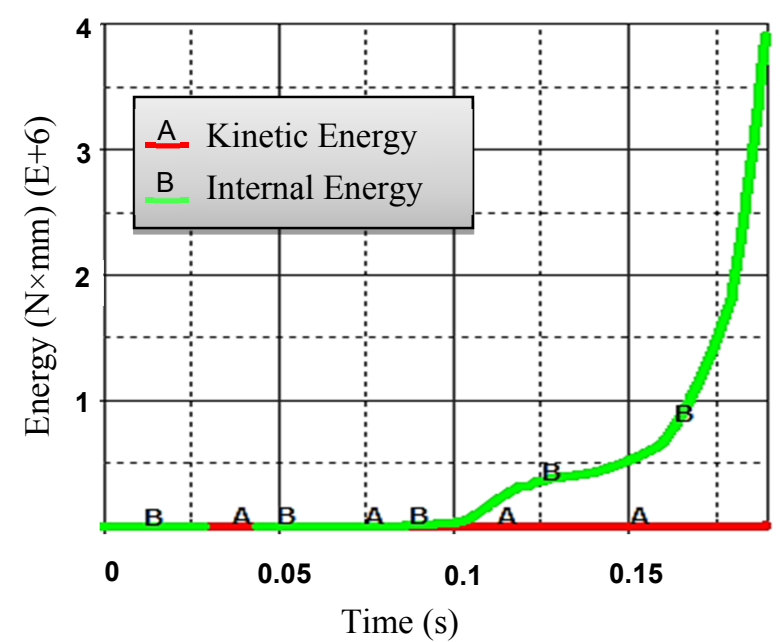

\section{Numerical and experimental results}

The numerical springback (N.S) and experimental springback (E.S) results were evaluated by measuring the springback angles, which is defined as the angle deviation from bending angles. Results were obtained for all the variation of bend angles and radii. Fig. 8 shows a sample result including part geometry and plastic strain distribution after springback.

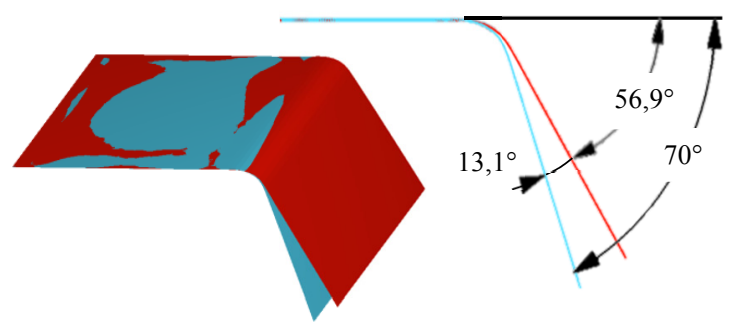

a)

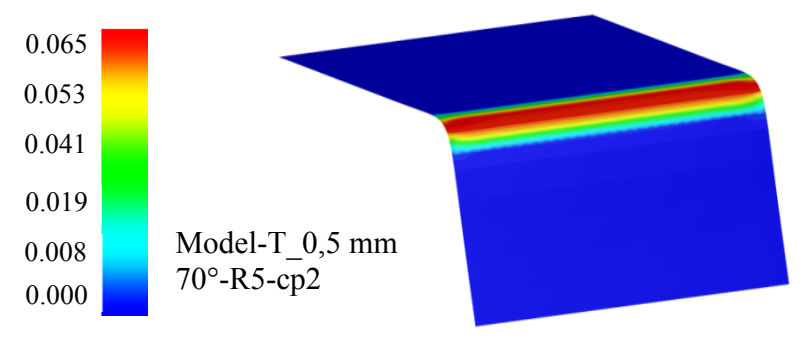

b)

Fig. 8. (a) Part after springback (b) Plastic strain distribution.

Numerical springback and experimental springback results, which were obtained by finite element analyses and experiments, are given in Table 2.

Table 2. Numerical springback (N.S) and experimental springback (E.S) results for the bending specimen.

\begin{tabular}{c|cc|cc}
\hline \multicolumn{5}{c}{ Bend Radius } \\
\hline \multirow{3}{*}{$\begin{array}{c}\text { Bend } \\
\text { Angle }\left[^{\circ}\right]\end{array}$} & N.S $\left[^{\circ}\right]$ & E.S $\left[^{\circ}\right]$ & N.S $\left[^{\circ}\right]$ & E.S $\left[^{\circ}\right]$ \\
\cline { 2 - 5 } & & & & \\
\hline 60 & 5.7 & 4.5 & 5.2 & 4.7 \\
70 & 5.8 & 6.7 & 13.1 & 11.3 \\
80 & 5.5 & 6.5 & 10.6 & 12.7 \\
90 & 6.6 & 6.0 & 11.8 & 12.1 \\
100 & 7.4 & 8.2 & 15.5 & 16.2 \\
110 & 8.8 & 9.9 & 16.5 & 18.8 \\
120 & 9.2 & 13.7 & 18.7 & 22.7 \\
\hline
\end{tabular}

In addition, graph of results is given in Fig. 9 for each bend radius and angle. As seen in the graph, the trend line of numerical results is compatible with the experimental results.

Fig. 7. Kinetic-internal energy control. 


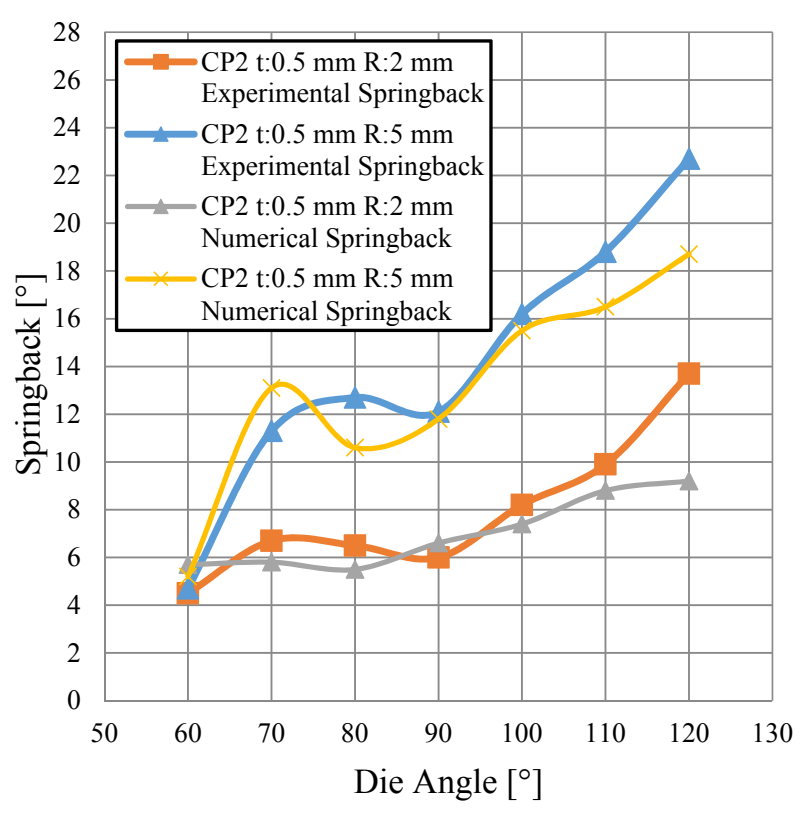

Fig. 9. Graph of result in Table 2.

It was hypothesized that the difference in experimental and numerical springback results can be due to a mismatch in the rate of forming of the parts on the hydroforming with membrane diaphragm and the strain rate at which material properties were conducted. In addition, springback is also influenced by many other parameters such as material thickness, die radius, ambient conditions and the speed of process, which is an important factor in creating dynamic effects and it affects the accuracy of the finite element analysis.

Furthermore, results show that the deviation of springback values between $70^{\circ}$ and $90^{\circ}$ bend angles are lower than the other intervals. This phenomenon could be explained by the diaphragm contact mechanics affecting on the blank material. For the acute bend angles, the diaphragm is in full contact with the blank, whereas for the obtuse bend angles, there is a region where the diaphragm loses its contact with the blank (Fig. 10). The gap observed is filled by the diaphragm reaching the maximum pressure. Consequently, this inconsistent contact between diaphragm and blank causes this unexpected trend shown in Fig. 9.

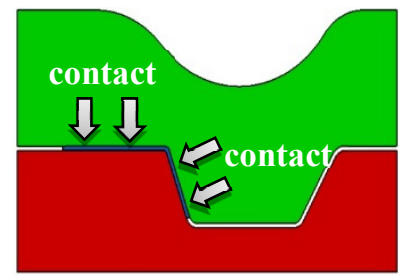

a)

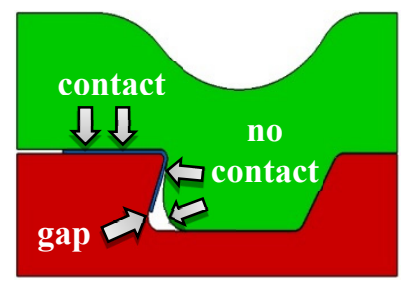

b)
Fig. 10. The diaphragm contact mechanics (a) for the acute bend angles (b) for the obtuse bend angles.

\section{Conclusion}

Finite element analysis was used to simulate the Hydroforming with Membrane Diaphragm process and to estimate the springback angles. Principally, the springback phenomenon can be minimized with suitable die modifications but cannot be eliminated. According to this study, the numerical and experimental springback results show good agreement. So, the springback values obtained from the numerical model can be used for die modifications in order to compensate springback and to get proper titanium productions.

The second outcome of this study is that the increment of springback angles does not follow a regular trend between $0^{\circ}$ and $120^{\circ}$ bend angles in this manufacturing process based on the numerical and experimental results. It is thought that this phenomenon occurs due to the nature of diaphragm contact mechanics.

This work was supported by TUSAŞ Aerospace Industries (TAI), Ankara, Turkey.

\section{References}

1. H.A. Hatipoglu, A.E. Tekkaya, Key Eng. Materials, 344, 469-476 (2007)

2. P. Kulkarni, S. Prabhakar, Proceedings of $4^{\text {th }}$ European Ls-Dyna Users Conference, 27-34 (2003)

3. H. Palaniswamy, G. Ngaile, T. Altan, J. Mater. Process. Technol, 146, 28-34 (2004)

4. M.H. Dirikolu, E. Akademir, J. Mater. Process. Technol, 148, 346-381 (2004)

5. M. Yamashita, T. Hattori, N. Nishimura, J. Mater. Process. Technol, 187, 192-196 (2007)

6. L. Noels, L. Stainier, J. Ponthot, J. Comp. and App. Math, 168, 331-339 (2004)

7. L.M. Kutt, A.B. Pifko, J.A. Nardiello, J.M. Papazian, Computers \& Structures, 66, 1-17 (1998)

8. J. Adamus, Int. J. of Applied Mechanics and Engineering, 11 , 727-733 (2006)

9. M. Mooney, J. Appl. Phys, 11, 582-597 (1940)

10. O.K. Demir, Technical paper. http://www.figes.com.tr/ls-dyna/, 2018 (Accessed 02.01.2018). 